\title{
Acceptability and feasibility of S-1 plus cisplatin adjuvant chemotherapy for completely resected non-small cell lung cancer: an open-label, single arm, multicenter, phase 2 trial
}

Shugo Uematsu

Showa University Northern Yokohama Hospital

Atsushi Sano

Toho University https://orcid.org/0000-0002-4604-9024

Kazutoshi Isobe

Toho University

Kazuhiro Usui

NTT Medical Center

Jun Matsumoto

NTT Medical Center

Takaharu Kiribayashi

Toho University

Kiyohaya Obara

Japan Self-Defense Force Central Hospital

Akihiko Kitami

Showa University Northern Yokohama Hospital

Yoshitaka Murakami

Toho University

Akira lyoda ( $\square$ aiyoda@med.toho-u.ac.jp )

https://orcid.org/0000-0002-0908-4840

Research article

Keywords: lung cancer, adjuvant chemotherapy, feasibility

Posted Date: July 24th, 2020

DOI: https://doi.org/10.21203/rs.3.rs-46057/v1

License: (c) (1) This work is licensed under a Creative Commons Attribution 4.0 International License.

Read Full License 
Page $2 / 18$ 


\section{Abstract \\ Background}

Although platinum-based chemotherapy is accepted as adjuvant chemotherapy for resectable advanced non-small cell lung cancer (NSCLC), its completion rate is low due to severe adverse events. S-1 plus cisplatin is associated with relatively low toxicity and an unimpaired quality of life, and has been used for unresectable advanced lung cancer. We investigated the acceptability and feasibility of combination therapy with S-1 plus cisplatin as postoperative adjuvant chemotherapy following complete resection of pathological stage II-IIIA NSCLC.

\section{Methods}

Enrolled patients received oral S-1 at a dose depending on their body weight twice daily for 21 days with intravenous cisplatin $60 \mathrm{mg} / \mathrm{m}^{2}$ on day 8 , with 1 cycle comprising 5 weeks and 4 cycles. Patients received standard precautions against adverse events and received standard treatment when adverse events occurred. The primary endpoint was completion rate; secondary endpoints included safety, status of drug administration, disease-free survival, and overall survival.

\section{Results}

A total of 19 patients [14 men, 5 women; mean age, 59.1 years; mean body surface area, $1.688 \mathrm{~m}^{2} ; 17$ with an Eastern Cooperative Oncology Group performance status (PS) of 0 and 2 with a PS of $1 ; 7$ (36.8\%) with stage II disease and $12(63.2 \%)$ with stage IIIA disease] were enrolled. The rate of completion of 4 cycles was $68.4 \%$. Grade 3 adverse events that occurred in $\geq 10 \%$ of patients included neutropenia (21.1\%), nausea (21.1\%), and anorexia (15.8\%). No grade 4 adverse events, febrile neutropenia, or treatment-related deaths occurred. The mean relative dose intensity was $79 \%$ for S- 1 and $80 \%$ for cisplatin. The 2-year disease-free survival rate was $42.1 \%$, and 2-year overall survival rate was $83.3 \%$.

\section{Conclusion}

This study demonstrated the acceptability and feasibility of using S-1 plus cisplatin as adjuvant chemotherapy.

\section{Background}

Lung cancer is a major cause of cancer death worldwide[1]. Globally, there were 20 million new cases of tracheal, bronchial, and lung cancer and 1.7 million deaths from these conditions in 2016, representing a 
28\% increase in incidence between 2006 and 2016[2]; thus, new developments in lung cancer treatment are essential.

According to a database of patients who underwent surgery in Japan [3], the 5-year survival rates of patients with stage IIA, IIB, and IIIA disease (reclassified with respect to clinical stage from the TNM classification seventh edition to the eighth edition) were $60.2 \%, 58.1 \%$, and $50.6 \%$, respectively. Distant metastasis was the most common form of recurrence in patients who had undergone complete resection, indicating that control of micrometastases at the time of resection improves prognosis of these patients. Therefore, adjuvant chemotherapy is the accepted standard of care, largely based on the results of several randomized trials and meta-analyses [4] [5] [6]. Adjuvant vinorelbine plus cisplatin is widely accepted as a standard regimen for completely resected non-small cell lung cancer (NSCLC). Although a subgroup analysis [7] of the LACE study [6] reported an 8.9\% 5-year survival improvement compared to surgery alone, the adjuvant therapy completion rate was $43 \%$ due to patient refusal and adverse events. Adverse events sometimes require reduced chemotherapy doses or even discontinuation. Among patients with stage I-III NSCLC, it has been reported that $42 \%$ of patients were expected to receive chemotherapy at a relative dose intensity $(\mathrm{RDI})<85 \%$ of the standard dose due to dose-limiting toxicities, but $63 \%$ of patients actually received an $\mathrm{RDI}<85 \%$ [8]. The inability to provide patients with a sufficient amount of drug may limit their survival outcomes.

S-1 is a tegafur-uracil-based, second-generation anticancer agent that contains tegafur, gimeracil (an inhibitor of dihydropyrimidine dehydrogenase, which decomposes fluorouracil), and oteracil (which inhibits the phosphorylation of fluorouracil in the gastrointestinal tract, thus decreasing associated gastrointestinal toxicity) in a 1:0.4:1 ratio [9]. Administration of S-1 monotherapy following complete resection of stage IB-IIIA NSCLC has been shown to be safe, with adequate compliance [10]. A randomized phase 3 study in Japanese patients with advanced NSCLC [11] demonstrated that survival associated with S-1 plus cisplatin was not inferior to that of docetaxel plus cisplatin, and both adverse events and quality of life were superior among patients who received S-1 plus cisplatin.

To sufficiently enhance the efficacy of chemotherapy, it is necessary to administer a sufficient amount of anticancer drugs. Despite the introduction of new agents and regimens, 5-year survival had improved < $10 \%$, and new treatment strategies and drugs are required to further improve the prognosis of patients with resectable NSCLC. We conducted a feasibility study of 4 courses of combination therapy with S-1 plus cisplatin (4 cycles) as postoperative adjuvant chemotherapy following complete resection of pathological stage II-IIIA NSCLC, with the objectives of reducing adverse events and increasing the completion rate.

\section{Methods}

\section{Eligibility criteria}


Patients with confirmed pathological stage II-IIIA NSCLC who had not received preoperative chemotherapy or radiotherapy and had undergone surgical treatment were enrolled. The eligibility criteria were: (1) pathologically confirmed NSCLC, (2) pathological stage II-IIIA (UICC-7 TNM lung cancer staging, 2009) disease, (3) pathological complete resection, (4) performance of ND2a or more extensive lymph node dissection, (5) no prior treatment other than surgery, (6) Eastern Cooperative Oncology Group performance status (PS) 0 or 1, (7) age $\geq 20$ years and $<75$ years, (8) no functional impairment of major organs, and laboratory test results showing $W B C \geq 3,000 / \mathrm{mm}^{3}$, leukocytes $\geq 1500 / \mathrm{mm}^{3}$, platelets $\geq 10^{5} / \mathrm{mm}^{3}$, hemoglobin $\geq 9.0 \mathrm{~g} / \mathrm{dL}$, AST $\leq 100 \mathrm{IU} / \mathrm{L}, \mathrm{ALT} \leq 100 \mathrm{IU} / \mathrm{L}$, total bilirubin $\leq 1.5 \mathrm{mg} / \mathrm{dL}$, and CCr $\geq 60 \mathrm{~mL} / \mathrm{min}$, (9) $\mathrm{PaO}_{2} \geq 65 \mathrm{mmHg}$ or $\mathrm{SpO}_{2} \geq 92 \%$, and (10) able to undergo chemotherapy within 8 weeks after surgery.

The exclusion criteria were: (1) serious drug allergy, (2) currently undergoing treatment with flucytosine, (3) pulmonary fibrosis or interstitial pneumonia, (4) infection requiring antibiotic treatment or poorly controlled complications, (5) serious diarrhea, (6) malignancy within the previous 5 years, (7) previous complete pneumonectomy, or (8) judged by the attending physician to be unsuitable for the study.

\section{Study design and treatment}

This study was a multicenter phase 2 clinical trial, for which registration started in February 2013 in five centers in Japan. It was approved by the Ethical Committee of Toho University Omori Medical Center (approved number: M17050), and conducted in accordance with the principles of the Helsinki Declaration. Written informed consent was obtained from all patients. Our study adheres to CONSORT guidelines. Patients were treated with S-1 twice daily for 21 days at an initial dose determined by body surface area (BSA) [BSA $<1.25 \mathrm{~m}^{2}: 40 \mathrm{mg} /$ dose (80 mg/day); $1.25 \leq \mathrm{BSA}<1.5 \mathrm{~m}^{2}: 50 \mathrm{mg} / \mathrm{dose}$ (100 mg/day); BSA $\geq 1.5 \mathrm{~m}^{2}: 60 \mathrm{mg} /$ dose (120 mg/day)] followed by a 14-day drug holiday, during which they were also given cisplatin $60 \mathrm{mg} / \mathrm{m}^{2}$ on day 8 . This 35-day period constituted 1 cycle, and treatment was repeated for 4 cycles. Pre- and post-treatment hydration and antiemetics were administered in accordance with the standard methods employed at each site. If at least 21 days had passed since the scheduled start date, the trial was continued unless a further adverse event requiring dose reduction occurred, even after a two-level reduction in the S-1 dose, when recurrence was observed, the patient requested the withdrawal of treatment, or the attending physician judged that the trial should not be continued for any other reason.

This study was registered on the UMIN clinical study registration site (protocol ID: UMIN000016191) on December 1, 2015.

\section{Outcome measures and statistical methods}

The objective of this study was to investigate the feasibility of using 4 courses (5-week cycles) of combination therapy with S-1 and cisplatin as postoperative adjuvant chemotherapy following complete resection of pathological stage II-IIIA NSCLC. The primary endpoint was the rate of completion of 4 treatment courses, and the secondary endpoints were safety, status of drug administration, disease-free 
survival (DFS), and overall survival (OS). OS was defined as the time from the date of surgery to death from any cause or final follow-up. DFS was defined as the time from the date of surgery to the date recurrence was determined or death from any cause, whichever came first, or the time to final follow-up. Safety was evaluated by calculating the frequency of the highest-grade adverse events, assessed by CTCAE v4.0-JCOG, in the analysis set comprising all patients who underwent treatment. The status of drug administration was evaluated by calculating the dose administered to patients and accounting for factors including drug holidays, dose reductions, and skipped doses, in the analysis set including all patients who underwent treatment. The total anticipated doses and actual dosage rates in this study were calculated as follows:

S-1: Total anticipated dose $=$ initial dose $(\mathrm{mg} /$ day) $\cdot$ total number of scheduled treatment days (days), actual dosage rate $(\%)=$ total dose administered during the treatment period $(\mathrm{mg}) /$ total anticipated dose $(\mathrm{mg}) \cdot 100$

Cisplatin: Total anticipated dose $=240 \mathrm{mg} / \mathrm{m}^{2}$, actual dosage rate $(\%)=$ total dose administered during the treatment period $(\mathrm{mg}) / 240\left(\mathrm{mg} / \mathrm{m}^{2}\right) \cdot 100$

The Kaplan-Meier method was used to describe DFS and OS. All statistical analysis was performed using JMP Pro 14 (SAS Institute., Cary, NC, USA).

\section{Results}

\section{Patient characteristics}

A total of 22 patients at 5 sites were enrolled between February 2013 and September 2017. Three were excluded as ineligible, and the patient characteristics of the remaining nineteen are shown in Table 1. They included 14 men and 5 women, with a mean age of 59.1 years (range, 49-63 years). All patients underwent lobectomy, including two cases of bilobectomy. A total of 7 patients (36.8\%) had stage II disease and 12 patients $(63.2 \%)$ had stage IIIA disease, and the pathological diagnosis was adenocarcinoma in 16 cases. The BSA was $<1.25 \mathrm{~m}^{2}$ in 1 case, $1.25 \leq \mathrm{BSA}<1.5 \mathrm{~m}^{2}$ in 4 cases, and BSA $\geq 1.5 \mathrm{~m}^{2}$ in 14 cases. 
Table 1

Patient characteristics $(n=19)$

\begin{tabular}{|c|c|c|c|}
\hline Characteristics & & $\mathbf{N}$ & $\%$ \\
\hline \multirow[t]{2}{*}{ Sex } & Male & 14 & 73.7 \\
\hline & Female & 5 & 26.3 \\
\hline Age, years & Median age (SD, range) & $59.1(7.63,49-63)$ & \\
\hline \multirow[t]{3}{*}{ BSA } & $<1.25$ & 1 & 5.3 \\
\hline & $1.25 \leq \mathrm{BSA}<1.50$ & 4 & 21.1 \\
\hline & $\geq 1.50$ & 14 & 73.7 \\
\hline \multirow[t]{2}{*}{ ECOG performance status } & 0 & 17 & 89.5 \\
\hline & 1 & 2 & 10.5 \\
\hline \multirow[t]{3}{*}{ Histology } & Adenocarcinoma & 16 & 84.2 \\
\hline & Squamous cell carcinoma & 1 & 5.3 \\
\hline & Other & 2 & 10.5 \\
\hline \multirow[t]{2}{*}{ Surgical procedure } & Lobectomy & 17 & 89.5 \\
\hline & Bilobectomy & 2 & 10.5 \\
\hline \multirow[t]{3}{*}{$\mathrm{p}$-Stage } & $\triangle \mathrm{A}$ & 4 & 21.1 \\
\hline & $\triangle \mathrm{B}$ & 3 & 15.8 \\
\hline & $\triangle \mathrm{A}$ & 12 & 63.2 \\
\hline \multicolumn{4}{|c|}{ ECOG, Eastern Cooperative Oncology Group. } \\
\hline \multicolumn{4}{|l|}{ BSA, Body surface area } \\
\hline p-Stage, pathological stage & & & \\
\hline
\end{tabular}

\section{Treatment Delivery and Safety}

Patients in this study underwent a total of 60 cycles. The completion rates and implementation status are shown in Table 2. Fourteen (73.7\%) patients completed 4 cycles. Three patients discontinued the study due to adverse events, which included grade 3 gastrointestinal symptoms (nausea) in all cases during the first cycle. Those patients refused to continue in the trial without accepting a dose reduction in the next cycle. Recurrence was detected after the completion of 2 cycles in 1 patient, and 1 patient discontinued treatment during the second cycle due to another disease (ruptured aortic aneurysm). The administration status of S-1 plus cisplatin is described in Table 3. Among patients who received more than 2 cycles, planned dose reduction was required in only 2 cases, with the doses of both S- 1 and cisplatin reduced in 
1 patient and only the dose of S-1 reduced in the other patient; both of these patients completed 4 cycles. The median RDI was $79 \% \pm 32 \%$ for S- 1 and $80 \% \pm 32 \%$ for cisplatin. Overall, $68.4 \%$ of patients achieved an actual $\mathrm{RDI} \geq 85 \%$.

Table 2

Patient Compliance with Chemotherapy $(n=19)$

\begin{tabular}{|lll|}
\hline Cycles completed by patients & $\mathbf{n}(\%)$ & Reason for discontinuation ( $\mathbf{n})$ \\
\hline Cycle 1 & $16(84.2)$ & Adverse event $^{a}(3)$ \\
\hline Cycle 2 & $15(78.9)$ & Other disease (1) \\
\hline Cycle 3 & $14(73.7)$ & Recurrence (1) \\
\hline Cycle 4 & $14(73.7)$ & \\
\hline No patient has discontinued due to serious chemotherapy-associated adverse events. \\
\hline
\end{tabular}

Table 3

Planned and Received Dose of S-1 plus Cisplatin

\begin{tabular}{|llllll|}
\hline N=19 & $\begin{array}{l}\text { Median Planned Total } \\
\text { S-1 dose, } \mathrm{mg} / \mathrm{m}^{2} \\
\text { (range) }\end{array}$ & $\begin{array}{l}\text { Median dose received, } \\
\mathrm{mg} / \mathrm{m}^{2}(75 \text { th } \\
\text { percentile) }\end{array}$ & $\begin{array}{l}\text { Median } \\
\text { RDI (\%) }\end{array}$ & $\begin{array}{l}\text { Mean } \\
\text { RDI } \\
(\%)\end{array}$ & $\begin{array}{l}\text { Proportion } \\
\text { with RDI } \\
\mathbf{2 8 5 \%}(\%)\end{array}$ \\
\hline S-1 & $10080(6720-10080)$ & $8760(4200-10080)$ & 100 & 79.0 & 68.4 \\
\hline Cisplatin & 240 & $240(120-240)$ & 100 & 80.3 & 68.4 \\
\hline
\end{tabular}

Table 4 lists the adverse events that occurred in all patients. Evaluated by worst grade, the most common adverse event was anemia (78.9\%), followed by nausea (68.4\%) and anorexia (63.2\%). Grade 3/4 adverse events included neutropenia (21.1\%), nausea (21.1\%), anorexia (15.8\%), and leukopenia (10.5\%); no grade 4 adverse event of any kind occurred, and there were no deaths due to adverse events. 
Table 4

Incidence of adverse events

\begin{tabular}{|c|c|c|c|c|c|c|}
\hline Grade & 1 & 2 & 3 & 4 & all & $\%$ \\
\hline \multicolumn{7}{|l|}{ Hematological } \\
\hline Leukopenia & 5 & 2 & 2 & 0 & 9 & 47.4 \\
\hline Neutropenia & 3 & 2 & 4 & 0 & 9 & 47.4 \\
\hline Anemia & 9 & 6 & 0 & 0 & 15 & 78.9 \\
\hline Thrombocytopenia & 7 & 0 & 0 & 0 & 7 & 36.8 \\
\hline febrile neutropenia & 0 & 0 & 0 & 0 & 0 & 0 \\
\hline \multicolumn{7}{|l|}{ Non-hematological } \\
\hline T-Bil elevation & 2 & 0 & 0 & 0 & 2 & 10.5 \\
\hline AST elevation & 5 & 0 & 0 & 0 & 5 & 26.3 \\
\hline ALT elevation & 4 & 0 & 0 & 0 & 4 & 21.1 \\
\hline Cr elevation & 3 & 0 & 0 & 0 & 3 & 15.8 \\
\hline Anorexia & 6 & 3 & 3 & 0 & 12 & 63.2 \\
\hline Nausea & 6 & 3 & 4 & 0 & 13 & 68.4 \\
\hline Vomiting & 4 & 0 & 0 & 0 & 4 & 21.1 \\
\hline Diarrhea & 3 & 2 & 1 & 0 & 6 & 31.6 \\
\hline Constipation & 4 & 2 & 0 & 0 & 6 & 31.6 \\
\hline General fatigue & 6 & 3 & 0 & 0 & 9 & 47.4 \\
\hline Stomatitis & 1 & 0 & 1 & 0 & 2 & 10.5 \\
\hline Edema & 2 & 0 & 0 & 0 & 2 & 10.5 \\
\hline Joint pain & 0 & 1 & 0 & 0 & 1 & 5.3 \\
\hline Mucositis & 0 & 0 & 0 & 0 & 0 & 0 \\
\hline Tears & 2 & 0 & 0 & 0 & 2 & 10.5 \\
\hline Rash & 0 & 0 & 0 & 0 & 0 & 0 \\
\hline Nervous system disorder & 0 & 0 & 0 & 0 & 0 & 0 \\
\hline Muscle pain & 0 & 0 & 0 & 0 & 0 & 0 \\
\hline Taste disorder & 1 & 1 & 0 & 0 & 2 & 10.5 \\
\hline
\end{tabular}


The median follow-up for the 19 patients was 926 days (95\% Cl: 646-1034). Recurrence occurred in 8 patients, and 3 patients died. Median DFS was 656 days (95\% Cl: $318-1116)$, and median OS could not be calculated due to the short observation time. Two-year DFS was $42.1 \%$, and two-year OS was $83.3 \%$ (Fig. 1).

\section{Discussion}

This study demonstrated the feasibility of combination therapy with S-1 plus cisplatin as postoperative adjuvant chemotherapy following complete resection of pathological stage II-IIIA NSCLC. The 4-cycle completion rate, the primary endpoint of this clinical trial, was $73.7 \%$, and no grade 4 adverse events or deaths occurred throughout the 4 cycles. The most common grade $3 / 4$ adverse events were neutropenia and gastrointestinal adverse events including nausea, vomiting, anorexia, and diarrhea. In addition, febrile neutropenia (FN) was not observed in any patient.

Two Japanese clinical trials of postoperative adjuvant chemotherapy with S-1 plus cisplatin have been reported [12] [13] (Table 5 shows the results of the present clinical trial and these two Japanese clinical trials). A phase 2 randomized trial comparing S-1 vs S-1 plus cisplatin (WJOG4108 trial) [12] reported a 4cycle completion rate of S-1 plus cisplatin arm of $74.7 \%$ and a 2-years DFS rate of $61 \%$. The incidence of grade 4 neutropenia was $5.3 \%$ and that of grade $3 \mathrm{FN}$ was $5.3 \%$, but there were no cases of grade $4 \mathrm{FN}$. The dosing schedule of S-1 plus cisplatin was S-1 $80 \mathrm{mg} / \mathrm{m}^{2}$ on 14 consecutive days and cisplatin $60 \mathrm{mg} / \mathrm{m}^{2}$ on day 1 , and the study population included $58.2 \%$ patients with stage II disease and $41.8 \%$ with stage III disease. The other phase 2 randomized trial, which evaluated S-1 vs S-1 plus cisplatin followed by S-1 (Okamoto et al.) [13], reported a completion rate of S-1 plus cisplatin followed by S-1 of $45.7 \%$ and a 2 -years DFS rate of $58.4 \%$. The incidence of grade $3 / 4$ neutropenia was $10.1 \%$, and no treatment-related deaths occurred. The dosing schedule of S-1 plus cisplatin followed by S-1 was S-1 $80 \mathrm{mg} / \mathrm{m}^{2}$ on 21 consecutive days and cisplatin $60 \mathrm{mg} / \mathrm{m}^{2}$ on day 8 every 5 weeks, followed by S-1 $80 \mathrm{mg} / \mathrm{m}^{2}$ on 14 consecutive days for 1 year, and registered patients included $62.3 \%$ with stage II disease and $37.7 \%$ with stage III disease. The 2-years DFS rate in the present study was $42.1 \%$, which is poor compared with these previous studies. Although the present results are limited due to the small number of patients, the different DFS rates are presumably due to different numbers of patients with advanced cancer registered in each study. More than half of the patients in the present study had pathological stage IIIA disease, so had a poorer prognosis than patients in previous studies (Table 5). However, despite the differences in the S-1 plus cisplatin administration schedules between these trials, no treatmentrelated deaths occurred. 
Table 5

Completion rate and adverse events in studies that evaluated in S-1 plus cisplatin, and E1505.

\begin{tabular}{|c|c|c|c|c|}
\hline Trial & Our study & $\begin{array}{l}\text { Iwamoto } \\
\text { 2015 } \\
\text { (WJOG } \\
\text { 4108) }\end{array}$ & $\begin{array}{l}\text { Okamoto } \\
2018^{13)}\end{array}$ & $\begin{array}{l}\text { WaKelee 2017 } \\
\text { (E1505) }\end{array}$ \\
\hline Target stage & $\|A-\| I A$ & $\|A-\| A$ & $\|A-\| A$ & IB-IIIA \\
\hline Study design & single arm & $\mathrm{RCT}$ & $\mathrm{RC}$ & $\mathrm{RC}$ \\
\hline $\begin{array}{l}\text { Chemotherapy } \\
\text { regimen }\end{array}$ & $\begin{array}{l}\text { S-1 plus } \\
\text { cisplatin }\end{array}$ & $\begin{array}{l}\text { S-1 plus } \\
\text { cisplatin } \\
\text { versus S-1 }\end{array}$ & $\begin{array}{l}\text { S-1 plus } \\
\text { cisplatin } \\
\text { followed by } \\
\text { S-1 versus S- } \\
1\end{array}$ & $\begin{array}{l}\text { VNR or DOC or GEM or PEM plus } \\
\text { cisplatin with non-BEV versus } \\
\text { VNR or DOC or GEM or PEM plus } \\
\text { cisplatin with BEV }\end{array}$ \\
\hline \multirow[t]{7}{*}{$\begin{array}{l}\text { Administration } \\
\text { schedule }^{a}\end{array}$} & $\begin{array}{l}\text { Cisplatin } \\
60 \mathrm{mg} / \mathrm{m}^{2} \\
\text { on day } 8\end{array}$ & $\begin{array}{l}\text { Cisplatin } \\
60 \mathrm{mg} / \mathrm{m}^{2} \\
\text { on day } 1\end{array}$ & $\begin{array}{l}\text { Cisplatin } \\
60 \mathrm{mg} / \mathrm{m}^{2} \\
\text { on day } 8\end{array}$ & \multirow{7}{*}{$\begin{array}{l}\text { Cisplatin } 75 \mathrm{mg} / \mathrm{m}^{2} \text { on day } 1 \\
\text { every } 3 \text { weeks VNR } 30 \mathrm{mg} / \mathrm{mg} \text { on } \\
\text { day } 1 \text { and day } 8 \text {, or DOC } \\
75 \mathrm{mg} / \mathrm{m}^{2} \text { day } 1 \text {, or GEM } \\
1200 \mathrm{mg} / \mathrm{m}^{2} \text { on day } 1 \text { and day } 8 \text {, } \\
\text { or PEM } 500 \mathrm{mg} / \mathrm{m}^{2} \text { on day } 1 \\
\text { every } 3 \text { weeks } \times 4\end{array}$} \\
\hline & $\begin{array}{l}\mathrm{S}-1 \\
80 \mathrm{mg} / \mathrm{m}^{2} \\
\text { day } 1-21\end{array}$ & $\begin{array}{l}\mathrm{S}-1 \\
80 \mathrm{mg} / \mathrm{m}^{2} \\
\text { day } 1-14\end{array}$ & $\begin{array}{l}\mathrm{S}-1 \\
80 \mathrm{mg} / \mathrm{m}^{2} \\
\text { day } 1-21\end{array}$ & \\
\hline & $\begin{array}{l}\text { every } 5 \\
\text { weeks }\end{array}$ & $\begin{array}{l}\text { every } 3 \\
\text { weeks }\end{array}$ & $\begin{array}{l}\text { every } 5 \\
\text { weeks }\end{array}$ & \\
\hline & $\times 4$ & $\times 4$ & $\times 4$ & \\
\hline & & & $\begin{array}{l}\text { followed by } \\
\text { S-1 }\end{array}$ & \\
\hline & & & $\begin{array}{l}80 \mathrm{mg} / \mathrm{m}^{2} \\
\text { day } 1-14 \\
\text { every } 3 \\
\text { weeks, }\end{array}$ & \\
\hline & & & for 1 year & \\
\hline $\begin{array}{l}\text { Pathological } \\
\text { stage } \\
\text { IB/IIA/IIB/IIIA }\end{array}$ & $0 / 4 / 3 / 12$ & $0 / 17 / 40 / 42$ & $0 / 21 / 16 / 33$ & $197 / 83 / 224 / 224$ \\
\hline Completion rate & $73.7 \%$ & $74.7 \%$ & $43.5 \%$ & n.d. \\
\hline $\begin{array}{l}\text { Adverse events } \\
(\%)\end{array}$ & G3/4 All & G3/4 All & G3/4 All & $\mathrm{G} 3 / 4$ \\
\hline
\end{tabular}

${ }^{a}$ S-1 plus cisplatin arm and vinorelbine or docetaxel or gemcitabine or pemetrexed plus cisplatin with non-bevacizumab arm.

VNR, vinorelbine; DOC, docetaxel; GEM, gemcitabine; PEM, pemetrexed.

G3/4, Grade 3 or Grade 4; n.d., no data. 


\begin{tabular}{|c|c|c|c|c|c|c|c|c|}
\hline \multirow{2}{*}{$\begin{array}{l}\text { Trial } \\
\text { Leukocytopenia }\end{array}$} & \multicolumn{2}{|c|}{ Our study } & \multicolumn{2}{|c|}{$\begin{array}{l}\text { Iwamoto } \\
2015^{12} \text { ) } \\
\text { (WJOG } \\
4108)\end{array}$} & \multicolumn{2}{|c|}{$\begin{array}{l}\text { Okamoto } \\
2018^{13)}\end{array}$} & \multicolumn{2}{|c|}{$\begin{array}{l}\left.\text { WaKelee } 2017^{15}\right) \\
\text { (E1505) }\end{array}$} \\
\hline & 10.5 & 45.4 & n.d. & n.d. & 1.4 & 46.4 & n.d. & n.d. \\
\hline Neutropenia & 21.1 & 45.4 & 27.4 & 79.0 & 10.1 & 59.4 & 33 & 66 \\
\hline Anemia & 0.0 & 78.9 & 8.4 & 55.8 & 5.8 & 92.8 & 7 & 44 \\
\hline $\begin{array}{l}\text { Platelet count } \\
\text { decreased }\end{array}$ & 0.0 & 36.8 & 2.2 & 28.5 & 2.9 & 53.6 & 4 & n.d. \\
\hline AST increased & 0.0 & 21.3 & n.d. & n.d. & 0.0 & 23.2 & n.d. & n.d. \\
\hline ALT increased & 0.0 & 21.1 & 0.0 & 28.5 & n.d. & n.d. & n.d. & n.d. \\
\hline Cr increased & 0.0 & 15.8 & 1.1 & 25.3 & 1.4 & 24.6 & 1 & 27 \\
\hline Nausea & 21.1 & 68.4 & 6.3 & 74.7 & 5.8 & 73.9 & 8 & n.d. \\
\hline Vomiting & 0.0 & 21.1 & 2.1 & 40.0 & 1.4 & 30.4 & 5 & n.d. \\
\hline Anorexia & 15.8 & 63.2 & 6.3 & 80.0 & 11.6 & 81.2 & 1 & n.d. \\
\hline Diarrhea & 5.3 & 31.6 & n.d. & n.d. & 4.3 & 27.5 & 3 & n.d. \\
\hline Fatigue & 0.0 & 45.4 & 4.2 & 58.9 & 5.8 & 60.9 & 10 & 20 \\
\hline $\begin{array}{l}\text { Febrile } \\
\text { neutropenia }\end{array}$ & 0.0 & 0.0 & 5.3 & 5.3 & n.d. & n.d. & 4 & 4 \\
\hline \multicolumn{9}{|c|}{$\begin{array}{l}\text { a } \mathrm{S}-1 \text { plus cisplatin arm and vinorelbine or docetaxel or gemcitabine or pemetrexed plus cisplatin with } \\
\text { non-bevacizumab arm. }\end{array}$} \\
\hline \multicolumn{9}{|c|}{ VNR, vinorelbine; DOC, docetaxel; GEM, gemcitabine; PEM, pemetrexed. } \\
\hline $\mathrm{G} 3 / 4, \mathrm{G}$ & ade $\angle$ & 1 & & & & & & \\
\hline
\end{tabular}

Neutropenia is the major dose-limiting toxicity of many chemotherapy regimens. FN is defined as neutropenia with fever, usually indicative of infection, and can be fatal. The mortality rate associated with FN has been estimated to be $9.5 \%$ [14]. In a nationwide prospective cohort study in the United States [8], FN occurred in $6.4 \%$ of patients in the first cycle of myelosuppressive chemotherapy, and cumulative events occurred over 4 cycles in $11 \%$ of patients. The JBR.10 study (inclusion period, 1994-2001) [4] and the ANITA study (inclusion period, 1994-2000) [5], which were analyzed in the LACE trial and led to the wide acceptance of the adjuvant vinorelbine plus cisplatin regimen, reported $73 \%$ and $85 \%$ rates of grade 3 and 4 neutropenia, respectively, and $7 \%$ and $9 \%$ rates of grade 3 and $4 \mathrm{FN}$, respectively. Recently, the results of the E1505 trial (inclusion period, 2007-2013) [15] were published. This study was a phase 3 randomized trial that compared the combination of vinorelbine, docetaxel, gemcitabine, and pemetrexed plus cisplatin with and without bevacizumab (BEV) as postoperative adjuvant chemotherapy after 
resection of pathological stage IB-III NSCLC. Not only was the addition of BEV ineffective in improving prognosis, but grade 3-5 adverse events occurred more frequently in the BEV arm. Rates of grade 3-5 neutropenia were $33 \%$ and $37 \%$ in the non-BEV arm and the BEV arm, respectively, and FN rates were $4 \%$ and $6 \%$, respectively. Thus, this study demonstrated that BEV should not be included in postoperative adjuvant chemotherapy regimens. Nevertheless, we gained important clinical value from that trial, because it was a cisplatin-based study with patient enrollment occurring from 2007-2013, and the precautionary measures and management methods for adverse events used were similar to those of the present study. Although the use of granulocyte-colony stimulating factor (G-CSF) was not reported, the incidence of adverse events is useful for comparison with those associated with S-1 plus cisplatin regimens (Table 5).

Recombinant human G-CSF stimulates production of mature, functional neutrophils. G-CSF agents have been shown to reduce the incidence of $\mathrm{FN}$ when used as prophylaxis following chemotherapy.

Pegfilgrastim has been reported to be effective as a primary preventive agent against FN in patients with advanced cancer receiving chemotherapy [16] and was approved for health insurance in Japan in 2014. In Japan, the use of pegfilgrastim in the adjuvant chemotherapy setting is not common, so the present study did not allow its use. Avoidance of FN, which may have a fatal outcome, is also important for avoiding changes to treatment schedules. The recommended regimens for adjuvant chemotherapy may change with the development of regimens predicated on the addition of pegfilgrastim, and their evaluation in future clinical trials is anticipated.

To sufficiently enhance the efficacy of chemotherapy, it is necessary to administer sufficient amounts of anticancer drugs. However, adverse events sometimes necessitate a reduction in the dosage of the drug and may require drug discontinuation. As mentioned in the Introduction, among patients with stage I-III NSCLC, it has been reported that $42 \%$ of patients are expected to receive chemotherapy at an RDI $<85 \%$ of the standard dose due to dose-limiting toxicities, but $63 \%$ of patients actually received an $\mathrm{RDI}<85 \%$ [8]. In the present study, $53 \%$ of patients were able to receive the planned dose, and $32 \%$ of patients received an overall actual RDI $<85 \%$. Thus, S-1 plus cisplatin appears to be a highly safe adjuvant chemotherapy regimen when administered using current standard precautionary measures for adverse events.

Clinical trials of S-1 plus cisplatin have tended to have high rates of gastrointestinal adverse events, and $\mathrm{S}-1$ alone is known to be associated with a high incidence of gastrointestinal adverse drug reactions. In a randomized clinical trial that compared the feasibility of 4 weeks of S-1 monotherapy followed by a 2week drug holiday with 2 weeks of S-1 monotherapy followed by a 1-week drug holiday as adjuvant chemotherapy [17], rates of nausea (all grades) were $39 \%$ vs. 38\%, respectively, and those of anorexia were $37 \%$ vs. $35 \%$, respectively, with no difference in incidence of gastrointestinal toxicity between the two treatment arms. In the E1505 study [15], however, the incidence of gastrointestinal toxicity was $<10 \%$, indicating that this form of toxicity is not necessarily characteristic of S-1. In the present study, 3 of 19 patients discontinued treatment during the first cycle due to gastrointestinal symptoms. Although it is unclear whether their reasons for dropping out were the dose of S-1 or the administration method, when 
S-1 is used in combination with cisplatin, the measures to improve gastrointestinal toxicity are required beginning soon after the start of administration.

Advanced recurrent lung cancer is currently treated strategically based on biomarkers, such as epidermal growth factor receptor, and molecular tumor profiles. However, the use of biomarkers and tumor profiles in selection of adjuvant chemotherapy is thus far rare. The JIPANG trial (UMIN000006737) [18], in which approximately 800 patients are being randomly allocated to receive either pemetrexed plus cisplatin or vinorelbine plus cisplatin as adjuvant chemotherapy following complete resection of non-squamous cell carcinoma, is currently underway in Japan. Not only is this trial expected to reveal whether or not there is any difference in prognosis, it may also potentially help improve patient prognoses by informing selection of adjuvant chemotherapy based on tumor type.

\section{Conclusions}

This study demonstrated S-1 plus cisplatin is associated with a low risk of life-threatening adverse events, such as FN. S-1 plus cisplatin may be a highly safe adjuvant chemotherapy regimen when given in conjunction with current precautionary measures for adverse events.

\section{Abbreviations}

BEV, Bevacizumab; BSA, body surface area; DFS, disease-free survival; FN, febrile neutropenia; G-CSF, granulocyte colony-stimulating factors; NSCLC, non-small-cell lung cancer; OS, overall survival; PS, performance status; RCT, randomized controlled study; RDI, relative dose intensity

\section{Declarations}

\section{Ethics approval and consent to participate}

This study was approved by the ethics committee of Toho University Omori Medical Center (approved number: M17050) and was registered on the UMIN clinical study registration site (protocol ID:

UMIN000016191) (Retrospectively registered).

https://upload.umin.ac.jp/cgi-open-bin/ctr/ctr_view.cgi?recptno=R000018790

Written informed consent was obtained from all patients.

\section{Consent for publication}

Not applicable

\section{Availability of data and materials}


All data generated or analyzed during this study are included in this published article.

\section{Competing interests}

There are no conflicts of interest to declare.

\section{Funding}

This research did not receive any specific grant from funding agencies in the public, commercial, or notfor-profit sectors.

\section{Authors' contributions}

SU, AS, KI, KU, JM, TK, KO, AK and Al have been involved in the conception and design of the study. SU and AS wrote the manuscript. SU, KI, KU, JM, TK, KO, AK collected data. YM made a statistical validation. Al supervised this study. All authors read and approved the final manuscript.

\section{Acknowledgements}

Not applicable

\section{References}

1. Bray F, Ferlay J, Soerjomataram I, Siegel RL, Torre LA, Jemal A. Global cancer statistics 2018 : GLOBOCAN estimates of incidence and mortality worldwide for 36 cancers in 185 countries. CA Cancer J Clin. 2018;68:394-424.

2. Global Burden of Disease Cancer Collaboration. Fitzmaurice C, Abate D, Abbasi N, Abbastabar H, Abd-Allah F, Abdel-Rahman O, et al. Global, Regional, and National Cancer Incidence, Mortality, Years of Life Lost, Years Lived With Disability, and Disability-Adjusted Life-Years for 29 Cancer Groups, 1990 to 2017: A Systematic Analysis for the Global Burden of Disease Study. JAMA Oncol. 2019;5:1749-68.

3. Okami J, Shintani Y, Okumura M, Ito H, Ohtsuka T, Toyooka S, et al. Demographics, Safety and Quality, and Prognostic Information in Both the Seventh and Eighth Editions of the TNM Classification in 18,973 Surgical Cases of the Japanese Joint Committee of Lung Cancer Registry Database in 2010. J Thorac Oncol. 2019;14:212-22.

4. Winton T, Livingston R, Johnson D, Rigas J, Johnston M, Butts C, et al. Vinorelbine plus cisplatin vs. observation in resected non-small-cell lung cancer. N Engl J Med. 2005;352:2589-97.

5. Douillard JY, Rosell R, De Lena M, Carpagnano F, Ramlau R, Gonzáles-Larriba JL, et al. Adjuvant vinorelbine plus cisplatin versus observation in patients with completely resected stage IB-IIIA non- 
small-cell lung cancer (Adjuvant Navelbine International Trialist Association [ANITA]): a randomised controlled trial. Lancet Oncol. 2006;7:719-27.

6. Pignon JP, Tribodet H, Scagliotti GV, Douillard JY, Shepherd FA, Stephens RJ, et al. Lung adjuvant cisplatin evaluation: a pooled analysis by the LACE Collaborative Group. J Clin Oncol. 2008;26:3552-9.

7. Douillard JY, Tribodet H, Aubert D, Shepherd FA, Rosell R, Ding K, et al. Adjuvant cisplatin and vinorelbine for completely resected non-small cell lung cancer: subgroup analysis of the Lung Adjuvant Cisplatin Evaluation. J Thorac Oncol. 2010;5:220-8.

8. Culakova E, Thota R, Poniewierski MS, Kuderer NM, Wogu AF, Dale DC, et al. Patterns of chemotherapy-associated toxicity and supportive care in US oncology practice: a nationwide prospective cohort study. Cancer Med. 2014;3:434-44.

9. Shirasaka T, Shimamato Y, Ohshimo H, Yamaguchi M, Kato T, Yonekura K, et al. Development of a novel form of an oral 5-fluorouracil derivative (S-1) directed to the potentiation of the tumor selective cytotoxicity of 5-fluorouracil by two biochemical modulators. Anticancer Drugs. 1996;7:548-57.

10. Okumura S, Sasaki T, Satoh K, Kitada M, Nagase A, Yatsuyanagi E, et al. Feasibility of adjuvant chemotherapy with S-1 consisting of a 4-week administration and a two-week rest period in patients with completely resected non-small cell lung cancer. Mol Clin Oncol. 2013;1:124-30.

11. Kubota K, Sakai H, Katakami N, Nishio M, Inoue A, Okamoto H, et al. A randomized phase III trial of oral S-1 plus cisplatin versus docetaxel plus cisplatin in Japanese patients with advanced non-smallcell lung cancer: TCOG0701 CATS trial. Ann Oncol. 2015;26:1401-8.

12. Okamoto T, Yano T, Shimokawa M, Takeo S, Yamazaki K, Sugio K, et al. A phase II randomized trial of adjuvant chemotherapy with S-1 versus S-1 plus cisplatin for completely resected pathological stage II/IIIA non-small cell lung cancer. Lung Cancer. 2018;124:255-9.

13. Iwamoto Y, Mitsudomi T, Sakai K, Yamanaka T, Yoshioka H, Takahama M, et al. Randomized Phase II Study of Adjuvant Chemotherapy with Long-term S-1 versus Cisplatin + S-1 in Completely Resected Stage II-IIIA Non-Small Cell Lung Cancer. Clin Cancer Res. 2015;21:5245-52.

14. Kuderer NM, Dale DC, Crawford J, Cosler LE, Lyman GH. Mortality, morbidity, and cost associated with febrile neutropenia in adult cancer patients. Cancer. 2006;106:2258-66.

15. Wakelee HA, Dahlberg SE, Keller SM, Tester WJ, Gandara DR, Graziano SL, et al. Adjuvant chemotherapy with or without bevacizumab in patients with resected non-small-cell lung cancer (E1505): an open-label, multicentre, randomised, phase 3 trial. Lancet Oncol. 2017;18:1610-23.

16. Cooper KL, Madan J, Whyte S, Stevenson MD, Akehurst RL. Granulocyte colony-stimulating factors for febrile neutropenia prophylaxis following chemotherapy: systematic review and meta-analysis. BMC Cancer. 2011;11:404.

17. Hata Y, Kiribayashi T, Kishi K, Nagashima M, Nakayama T, Ikeda S, et al. Adherence and feasibility of 2 treatment schedules of S-1 as adjuvant chemotherapy for patients with completely resected advanced lung cancer: a multicenter randomized controlled trial. BMC Cancer. 2017;17:581. 
18. Yamamoto N, Kenmotsu H, Yamanaka T, Nakamura S, Tsuboi M. Randomized Phase III. Study of Cisplatin With Pemetrexed and Cisplatin With Vinorelbine for Completely Resected Nonsquamous Non-Small-Cell Lung Cancer: The JIPANG Study Protocol. Clin Lung Cancer. 2018;19:e1-3.

\section{Figures}
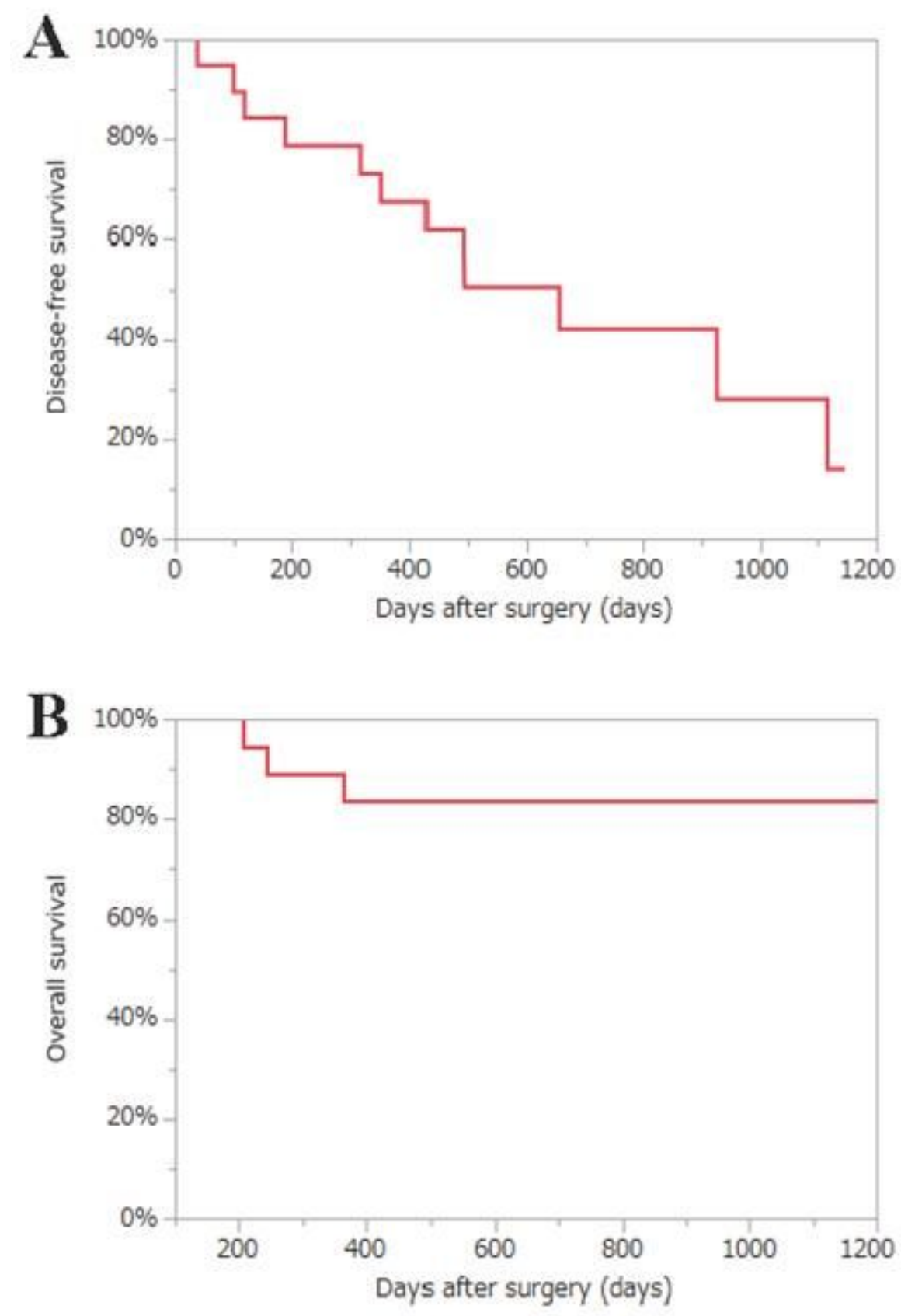

\section{Figure 1}

Disease-free survival and overall survival A) Disease-free survival curve Median, 656 days $₫ 21.8$ months $₫$ Range, 38-1146 days 2-year DFS: $42.1 \%$ B) Overall survival curve for all patients Range, 166-1478 days 2year OS: $83.3 \%$ 


\section{Supplementary Files}

This is a list of supplementary files associated with this preprint. Click to download.

- CONSORT2010Checklist.doc 